\title{
Bridging the gap: integrating external knowledge from open innovation platforms
}

\author{
Marion A. Weissenberger-Eibl ${ }^{1} \cdot$ Tim Hampel $^{1}$ (D)
}

Received: 12 January 2021 / Accepted: 27 May 2021 / Published online: 28 June 2021

(C) The Author(s) 2021

\begin{abstract}
While external knowledge has the potential to benefit a firm's innovation activities, research shows that the positive effects of a more open model of innovation do not come naturally. This paper draws on the project level to explore the organizational factors that hamper or impede the integration of external knowledge sourced from an open innovation platform and to suggest interventions to overcome these barriers. While open innovation is mainly discussed as a concept that resides at the level of the organization, this paper draws on the project level to contribute to a multilevel understanding of open innovation and to offer a deeper understanding of the challenges project teams face, when integrating external knowledge. To investigate occurring barriers, four cases of external knowledge integration within a multinational corporation are analyzed. The results show that due to the external nature of the knowledge, an additional effort of project teams is required such as forming alliances with key individuals and changing negative attitudes towards external sources to overcome organizational resistance. Theoretical as well as practical implications are discussed.
\end{abstract}

Keywords Open innovation platforms · Not-Invented-Here $\cdot$ Barriers to innovation · Absorptive capacity $\cdot$ Knowledge transfer

\section{Introduction}

Staying innovative over time in complex and volatile environments is a major challenge for organizations in different industries alike. In their efforts to develop new products, services, or processes, firms have incorporated knowledge, ideas, or technologies from external sources for decades (Trott and Hartmann 2009). However, since the term open innovation (OI) was coined, firms increasingly started to search

Tim Hampel

Tim.Hampel@gmx.net

1 Department of Innovation and Technology Management, Karlsruhe Institute of Technology (KIT), Fritz-Erler-Str. 1-3, 76133 Karlsruhe, Germany 
for external input on a larger scale (Chesbrough 2003; Enkel et al. 2009). Research in the area of OI emphasizes that external actors hold potentially valuable knowledge which may spur internal problem solving and innovation (Dahlander and Frederiksen 2011; Nylund et al. 2020). Incorporating external knowledge can enable firms to connect formerly disparate ideas and therefore unlock significant commercial potential (Baron 2006; Dahlander and Frederiksen 2011). To tap into the creative potential of external actors, a vast number of firms have implemented dedicated platforms and programs to search for knowledge outside the firm's boundaries (Brunswicker and Chesbrough 2018; Bogers et al. 2018a). P\&G's "Connect + Develop" platform, Lego's "Ideas" platform, or NASA “Tournament Lab" platform are examples of how large corporations search for and engage with external knowledge (Ozkan 2015; Andersen and Gadde 2019; Devece et al. 2019). Lego, for example, has already realized 34 products which have been suggested by the crowd and Dell has implemented more than 548 ideas from participating users of their IdeaStorm platform (Schlagwein and Bjorn-Andersen 2014; Hossain and Islam 2015). Therefore, open innovation platforms are set up to enable crowds to engage for various purposes such as idea generation, problem-solving, or discussion. However, despite the potential benefits and growing popularity of OI platforms, their effectiveness has been questioned recently (Cheng and Huizingh 2014; Miozzo et al. 2016; Stanko et al. 2017). In a study of 121 large firms in the U.S. and Europe, Brunswicker and Chesbrough (2018) found that closed innovation projects still share higher success rates compared to OI projects. Additionally, the number of reports about failure cases and firms that turn back their OI activities seems to grow in recent years (von Briel and Recker 2017; Hewitt-Dundas and Roper 2017). These findings indicate that a more open model of innovation does not per se lead to higher levels of innovation performance. Searching knowledge (ideas, technologies) from external actors via OI platforms is only a first step to benefit from open innovation as this knowledge has to be absorbed, i.e. recognized, assimilated and transformed by the individual members of the firm (Cohen and Levinthal 1990; Zahra and George 2002). As OI platforms are set up to improve the identification and acquisition of external knowledge through sourcing activities and pilot programs it can be argued that, at best, they enhance the early phase of the absorption process. Hence, the prevailing question remains how firms successfully integrate and commercialize external knowledge sourced from OI platforms. As firm internal project teams are usually responsible for transforming external ideas into products or services for commercialization (Kim et al. 2015; Midler et al. 2016), the project level becomes especially important in investigating the process of external knowledge absorption.

The purpose of this paper is to identify the factors that hamper or impede the integration of externally sourced knowledge via an OI platform at the project level and to derive suggestions for practical interventions to remove these barriers. Therefore, four cases of external knowledge integration from an OI platform of an MNC_-referred to as Jupiter in the following-have been analyzed. By means of this multiple-case study approach (Creswell 2012; Yin 2018), the paper contributes to the state of the literature in primarily three ways.

First, it responds to calls for more research on how to develop organizations to support cooperation with external actors (Tucci et al. 2016; Ghezzi et al. 2018; 
Foege et al. 2019). While most large firms have implemented dedicated platforms and programs to source external knowledge, relatively little is known about the hurdles organizations face when integrating promising external ideas and technologies into the innovation process (Monteiro et al. 2017). Second, past studies mainly explored the antecedents, mechanisms, and outcomes of OI at the firm level (Foss et al. 2013; Salter et al. 2014; Bogers et al. 2018b). Therefore, research advocates the need to further explore the multi-level processes of OI (Bogers et al. 2017). Since OI activities are usually organized as projects (Kim et al. 2015; Midler et al. 2016), this paper draws on the project level to offer a deeper understanding of the challenges project teams face when integrating external knowledge. Third, the paper addresses a well-known but little investigated barrier of integrating external knowledge- - the Not-Invented-Here (NIH) syndrome (Katz and Allen 1982; Lichtenthaler and Ernst 2006; Antons and Piller 2015). The research exemplifies the occurrence and persistence of the NIH syndrome during external knowledge integration and shows how the NIH syndrome is leading to project failure, but at the same time, it provides exemplary measures on how NIH tendencies can be overcome (Weissenberger-Eibl and Hampel 2021).

The remainder of the article continues as follows. It depicts the conceptual background of the research and briefly reviews the literature on open innovation, absorptive capacity, and the barriers' approach to innovation. Thereafter, it describes the research setting and methodology that structured the investigation. Following the methodological part, it presents the results of four cases of external knowledge integration within an MNC. The paper ends with the discussion, contribution to theory and practice, suggestions for further research, and a conclusion of findings.

\section{The challenge of integrating external knowledge: conceptual background}

\section{Closed versus open models of innovation}

Following a closed innovation model, firms rely on internal R\&D where the entire new product development cycle is integrated within the company, reasoning that successful innovation requires ownership and control (Gassmann 2006; Almirall and Casadesus-Masanell 2010). In this paradigm, firms develop, built, and market novel ideas on their own with little to none support from the external environment (Chesbrough 2004). OI models, in contrast, are grounded in the idea that external sources hold critical knowledge which may accelerate a firm's innovation activities (Enkel et al. 2009; West et al. 2014). This model of innovation has received great attention from research and practice in recent years and has become especially important for the innovation strategy among organizations of all sizes (Arora and Gambardella 2010; Monteiro et al. 2017; Brunswicker and Chesbrough 2018). On a broad level, OI is defined as the use of purposive inflows and outflows of knowledge, ideas, and technologies by firms to accelerate internal innovation and expand the markets for the external use of innovation (Chesbrough 2003, 2006). According to prior research, OI approaches entail two distinct advantages. First, external 
knowledge fosters problem-solving activities by enriching the firm's knowledge base and second, it benefits innovation by providing the possibility to conduct a combinatory search (Nelson and Winter 1990; Katila and Ahuja 2002; Monteiro et al. 2017). Therefore, external knowledge can potentially lead to higher levels of innovation performance when this knowledge is processed and coupled with firm internal expertise (Gibb 2002; Hargadon and Fanelli 2002; Weissenberger-Eibl 2019). In doing so, OI can help firms to overcome the familiarity trap by challenging firm internal routines (Cassiman and Veugelers 2006; Monteiro et al. 2017). Although the benefits of a more open approach to innovation have been investigated and demonstrated by previous research (Laursen and Salter 2006; Leiponen and Helfat 2010), more recent studies emphasize that openness has its limits in fostering firm internal innovation activities (Almirall and Casadesus-Masanell 2010; Tucci et al. 2016; von Briel and Recker 2017).

\section{Organizational barriers to 01}

On the level of the organization, several barriers that hamper or impede the shift to a more open model of innovation have been identified by previous research such as overcoming cultural path dependencies (Herzog and Leker 2010), the identification of relevant external partners (Dyer and Singh 1998; Brunswicker and Vanhaverbeke 2015), legal and regulatory constraints (Enkel et al. 2009; Mergel and Desouza 2013), financial constraints (van de Vrande et al. 2009), or conflicting demands of control and openness (Lauritzen and Karafyllia 2019; Foege et al. 2019). Moreover, firms that managed to overcome these initial barriers of opening up the innovation process face the challenge of integrating external knowledge for internal innovation (Nylund et al. 2020).

Integrating external knowledge deviates from internal development cycles in two distinct ways. First, external knowledge most often differs from internal language and expertise and has to be transformed in the first place to make it applicable (von Hippel 1994; Kostova 1999). Second, the maturity level of external knowledge may range from (product) ideas to technological solutions offered by external actors for commercialization (Lin et al. 2012; Foss et al. 2013). Therefore, external knowledge may not be easily integrated into an established (stage-gate) process due to a transformative up-front effort (Cooper 1990; Lin et al. 2012). Hence, barriers with regard to integrating external knowledge may deviate from barriers in intra-organization knowledge transfer (e.g. between regionally divided organizational entities) (Birkinshaw and Ridderstråle 1999; Seus et al. 2020).

To benefit from the expertise of outsiders, external knowledge has to be absorbed-acquired, assimilated, transformed and exploited-by firms to make it commercially applicable (Cohen and Levinthal 1990; Zahra and George 2002). Previous research has identified several firm-level antecedents that are related to a firm's absorptive capacity. Leiponen and Helfat (2010), for example, found that access to a broad external network is associated with higher levels of knowledge absorption. Firms with a diverse network of external partners are more likely to be exposed to potentially valuable knowledge, which positively affects the recognition, 
transformation and exploitation of new knowledge, ideas or technologies (Leiponen and Helfat 2010; Lowik et al. 2017). Furthermore, organizational coordination capabilities such as cross-departmental and cross-functional interfaces, job rotation programs, and participation in decision-making have been shown to enhance a firm's potential absorptive capacity. On the other hand, mechanisms that foster firm internal socialization and connectedness are associated with increased levels of a firm's realized absorptive capacity (Jansen et al. 2005; Cruz-Ros et al. 2018). However, although a firm's leadership and strategic direction can set the agenda for opening up corporate innovation activities, the actual conduct of a successful integration of external knowledge depends "on the absorptive capacities of its individual members" (Cohen and Levinthal 1990: 131). Here, firms usually approach OI in a structured way by defining a project team responsible for integrating external knowledge (Chiaroni et al. 2010; Pellizzoni et al. 2019). This team-centered approach, most firms share, make it particularly important to develop a deeper understanding of the challenges project teams face when integrating external knowledge from OI platforms (Pellizzoni et al. 2019).

\section{OI platforms and project-level barriers to external knowledge integration}

In their attempt to shift to an OI model and absorb external knowledge, firms have implemented digital (internet-based) as well as physical (event-based) OI platforms (Hilbolling et al. 2020). These platforms are set up to identify and attract valuable external knowledge for internal problem solving and innovation activities (Kozinets et al. 2008; Jeppesen and Lakhani 2010). In contrast to innovation communities, which are characterized by a loosely coupled cooperation of voluntary actors who share a vast interest in the phenomena of innovation (West and Lakhani 2008; Kozinets et al. 2008), OI platforms seek to fuel the firm's own innovation pipelines (Frey et al. 2011). These platforms are either run by firms itself or an intermediary who acts as virtual knowledge brokers for firms (Sawhney et al. 2003; Jeppesen and Lakhani 2010). Whether OI platforms appear in a digital or physical format or are run by the firm itself or an intermediary, they share the common goal of attracting external knowledge for internal innovation (von Briel and Recker 2017). Given the purpose of these platforms - the search and acquisition of potentially valuable external knowledge - this is only a first step to benefit from OI and the question remains how to integrate external knowledge successfully into the firm's innovation process.

Typically, OI is put into practice on the level of projects where a dedicated project-team processes and integrates the external knowledge (Kim et al. 2015; Midler et al. 2016). Here, previous research has structured barriers to the integration of external knowledge on a rather broad level, which makes it particularly challenging to make these barriers tangible and to derive practical recommendations. Especially two problems of integrating external knowledge on the project level have been discussed. First, in an OI paradigm, the knowledge base of the recipient firm and the knowledge holder may differ, making it difficult for project teams to assimilate and transform the external knowledge (Schwenk and Weissenberger-Eibl 2009; Lakemond et al. 2016). In this vein, external knowledge has been described to be "sticky" 
to the context in which it was first developed. Therefore, external knowledge is often incompatible with internal capabilities, language, and expertise (von Hippel 1994; Ter Wal et al. 2017). Second, due to the external nature of the knowledge, negative attitudes with regard to the knowledge source may lead to underutilization or rejection of the knowledge despite being of considerable potential value (Lichtenthaler and Ernst 2006; Kathoefer and Leker 2012). This negative attitude of employees towards external knowledge is called the Not-Invented-Here (NIH) syndrome and is one of the most cited problems in innovation management research and practice (Antons and Piller 2015; Antons et al. 2017). Especially at the project level, previous research emphasizes the separation of project teams from external sources and the rejection of external knowledge due to a potential threat to the team's expert status (Katz and Allen 1982; Allen et al. 1988). Besides the well-known disturbing effects of the NIH syndrome on the absorption of external knowledge, research on the phenomenon itself and — arguably most importantly_on possible countermeasures, remains scarce (Hannen et al. 2019).

Therefore, the objective of this paper is to obtain a deeper understanding of the barriers project teams face when integrating external knowledge and to derive interventions to overcome these barriers. In line with the literature on innovation management, a barrier is defined as an issue that either hampers, delays or impedes innovative activities within organizations (Larsen and Lewis 2007; Pablo et al. 2012). To investigate occurring barriers and suggest interventions, four empirical cases of external knowledge integration within Jupiter, an MNC of the automotive industry, have been analyzed.

\section{Research setting}

\section{Methodological approach}

This study employed an exploratory research approach, as very limited is known so far about the project-level barriers and success factors of external knowledge integration from OI platforms. To shed light on these aspects, a qualitative case study approach was chosen which allows it to obtain data from various sources such as personal interviews, field notes, or direct observations that in combination inform the study's focal purpose (Creswell 2012; Yin 2018). To comprehensively investigate occurring barriers and success factors, a contrast of different cases becomes necessary. Therefore, this study investigated multiple cases of external knowledge integration within a single firm. Multiple-case analysis provides the possibility not only to observe a phenomenon from various perspectives but also to strengthen the methodological rigor of the investigation (Eisenhardt 1989; Stake 2005). Especially in situations where novel organizational instruments and methods have been introduced, multiple-case studies are considered particularly appropriate to investigate their effectiveness and acceptance (Miles and Huberman 1994). In this sense, multiple-case analysis can be distinguished into two classes. On the one hand, developing case studies focus on a close collaboration of the researcher with dedicated individuals of the firm to observe and understand emerging phenomena during the 
implementation process of new methods. On the other hand, extracting case studies focus on analyzing patterns of organizational phenomena with the aim to derive managerial recommendations for problem solving and refinements (Aken 2005). This research followed the latter type to examine the challenges managers and project teams face when integrating external knowledge from OI platforms through (1) extensive semi-structured face-to-face interviews as a primary data source and (2) multiple data sources including internal information, informal conversations, field notes, and relevant newspaper article.

\section{Data collection, data analysis and empirical setting}

The investigated MNC is located with its headquarter in Germany and belongs to the automotive industry. The company was chosen as subject to this study due to its intense OI activities and several years of experience with an in-house OI platform. For reasons of confidentiality, the company name has been removed. In the following, the organization will be referred to as "Jupiter". Four cases of external knowledge integration within Jupiter are analyzed in this study. Within the year of data collection, the total number of external knowledge projects considered for integration was five. Therefore, our sample reflects a major proportion (80\%) of the total projects concerned with external knowledge. Purposive sampling was used to ensure that the selected cases offer insights into the phenomenon of interest (Creswell 2012). Therefore, the selection of cases in the purposive sample was based on three criteria. First, a 50:50 mix of successful and unsuccessful cases of external knowledge integration to contrast findings. Second, projects of external knowledge integration should not be completed longer than 6 months ago due to memory reasons of respondents. Third, with regard to the focal point of the study, only cases have been considered where external knowledge entered the company via the firm's OI platform. This sampling strategy was chosen to ensure cross-case comparability and to improve the credibility of the cases. Table 1 provides an overview of the selected cases. Each case represents a project in which a dedicated team of Jupiter was involved to integrate the external solution. The first case was concerned with a technical solution from a supplier to improve the handling of lightweight robotic production systems via a newly designed user interface. The second case dealt with an improved vehicle navigation system sourced from a startup. The third case was about a trip planning software for electric vehicles that connects drivers to near-by charging stations from a startup. The fourth case dealt with a cashless parking solution via a Near Field Communication (NFC) chip developed by a startup.

The data collection spanned over a period of 8 months and was collected between August 2018 and March 2019. During this time, data from newspaper articles, internal information, informal conversations, and interviews were collected. Interviews as the primary data source were conducted on the company's premises. All interviews were face-to-face and approved by the participants themselves as well as the firm's works council. Participants were interviewed independently of each other to ensure privacy and to avoid biases in responses. Following each interview, participants were asked for further potential candidates who contributed to the integration. 


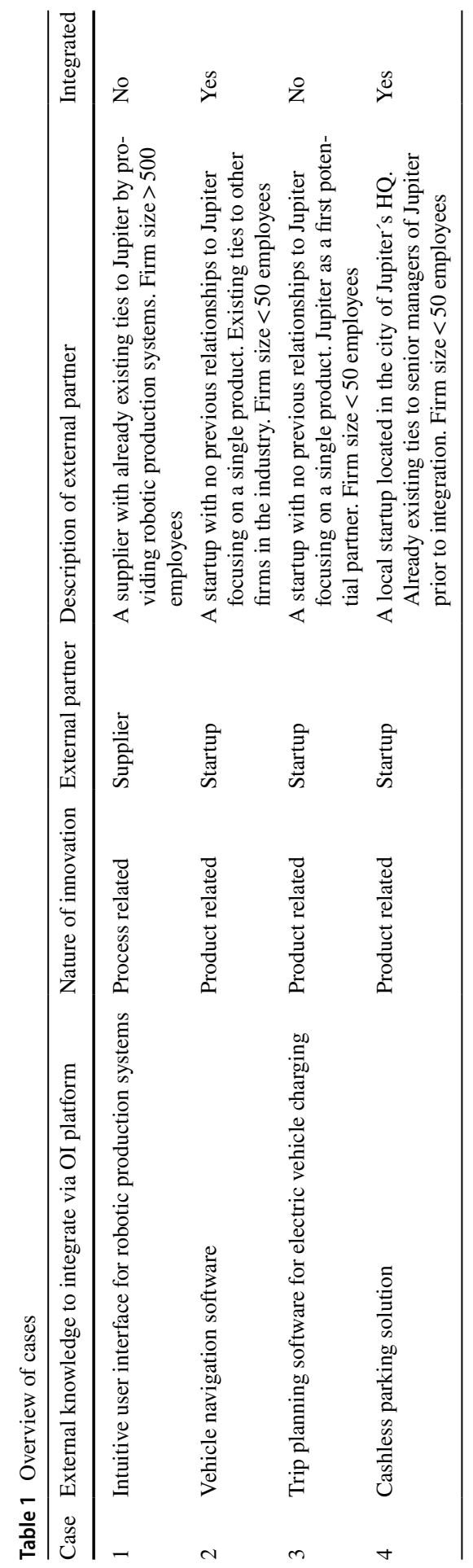

SN Business \& Economics 
In total, 23 face-to-face interviews were conducted. Two interviews took place with managers of the OI platform to develop a comprehensive understanding of the structure and operation of the firm's OI platform. 21 face-to-face interviews were conducted on the four cases with project participants including project managers, technical experts and participants from other departments involved in the projects. An overview of informants can be found in Table 2.

The interviews lasted between 40 and $90 \mathrm{~min}$ and included a variety of aspects around the process of external knowledge integration (see "Appendix 1" for the interview guidelines). As participants represented different organizational functions and hierarchies, questions were adapted to meet the specific expertise and hierarchical position of the respondents. Aspects captured in every interview dealt with questions about the overall project satisfaction, critical decision-making situations and other key events.

All interviews were recorded and transcribed verbatim to ensure the reliability of the results. In the phase of analysis, the researchers looked for common patterns across the cases with regard to challenges and success factors of the project teams during the integration process. The interview material was approached through a thematic analysis process. This procedure included the following steps: (1) data familiarization, (2) coding, (3) thematic search, (4) theme definition and naming and, (5) report generation (Braun and Clarke 2006; Dillworth et al. 2019). After familiarizing with the data, the interview material was approached without a predefined coding system to meet the exploratory nature of the research. Therefore, an open coding process using in vivo coding was chosen. Specifically, repeatedly mentioned terms by participants were used as codes to identify common themes across cases. (Creswell 2012; Dillworth et al. 2019). To ensure the methodical rigor of the analyzing and coding procedure, thematic codes were structured and listed in a document. These codes were reviewed by a second qualitative researcher with the aim of at least $80 \%$ congruency to ensure inter-coder reliability (Creswell 2012; Dillworth et al. 2019). The interview material was reviewed until thematic saturation. Afterwards, the cases were contrasted to identify common patterns as well as differences with regard to project-level challenges and success factors. During this phase, interview analysis was supplemented by information from field notes of informal conversations and internal project reports to facilitate triangulation and validation of the data (Maxwell 2012). Therefore, the secondary data (which were not coded) provided additional information on the cases as they included comments such as additional remarks of the respondents about their personal perception of the challenges and strategies to possibly resolve them. In sum, the different data sources helped to validate the emerging themes through triangulation and to minimize the perception biases of the researchers (Yin 2018). 


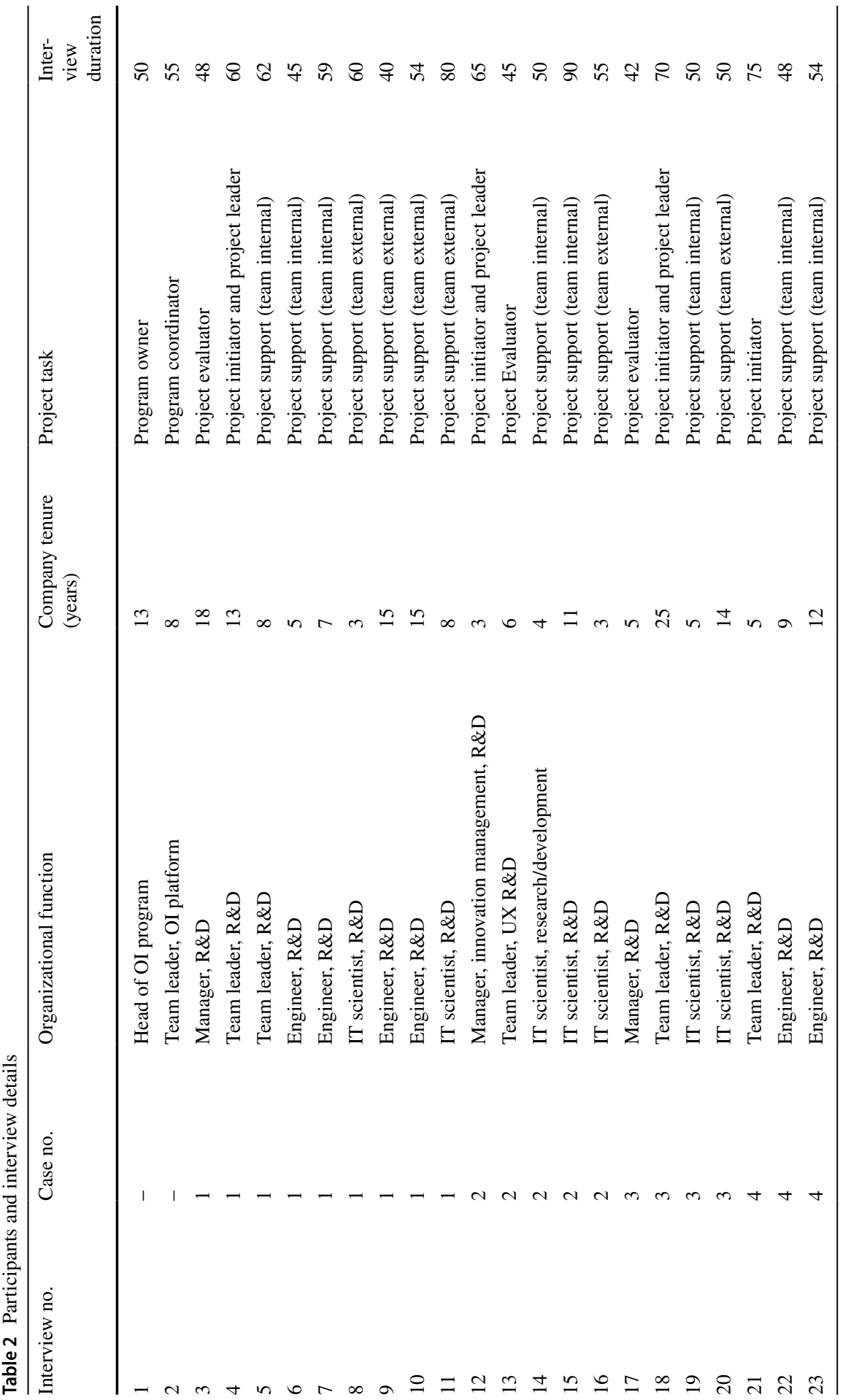

SN Business \& Economics 


\section{Results}

\section{Jupiter's Ol platform}

Based on the results of the interview analysis with managers responsible for the firm's OI activities and the analysis of internal documents and relevant newspaper articles, Jupiter's initial motivation of establishing an OI platform in 2013 and thus, opening up the innovation process were twofold. First, an incipient transformation process within the automotive industry regarding stricter regulations (emissions standards), new powertrain concepts (electrification), increasing servitization (mobility-on-demand), and the increasing relevance of software technologies forced Jupiter to broaden its knowledge base by tapping into external knowledge sources. Second, while in the past, Jupiter followed a closed innovation model with remarkable expenditures in research and development, severe competition in the automotive industry also served as a trigger to reconfigure innovation activities.

Jupiter's OI platform is embedded into the firm's so-called "OI program" which constitutes the firm's external knowledge sourcing and integration activities. Similar to most OI platforms, Jupiter's platform provides a digital front-end that serves as an interface between Jupiter and external knowledge holders. Additionally, the platform's appearance (basically its name) is used as an umbrella under which a dedicated four-stage process was developed to source external knowledge and to prepare its integration. The platform is hosted by a dedicated team of Jupiter located in its $\mathrm{R} \& \mathrm{D}$ division. The content (e.g. calls for dedicated problems or ideas for product features) is managed by the team itself. Although located in Jupiter's R\&D division, external problem solving or ideas are not limited to R\&D only. The responsible manager of Jupiter's OI program summarizes the platforms' role as: "The focal place where we post relevant questions, external solutions can be submitted, and integration is prepared" ([1] Head of OI program). The descriptive logic of Jupiter's OI program is depicted in Fig. 1.

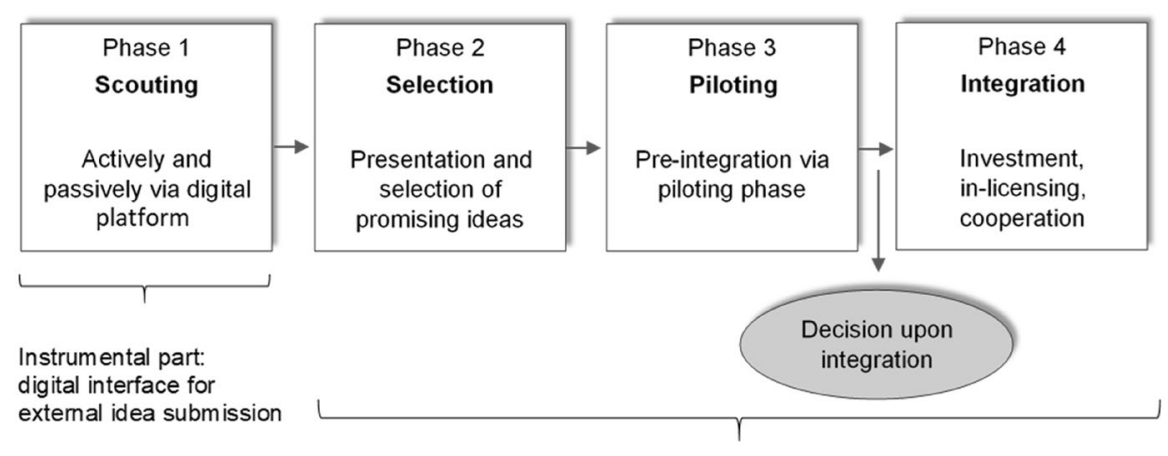

Process part: using the platforms appearance to prepare integration

Fig. 1 Jupiter's external knowledge sourcing and integration process 
In phase 1, which lasts around 3 months, a dedicated team of Jupiter called "open innovation" is actively scouting promising external ideas and technologies concerning a specific, pre-defined topic. In parallel, external actors are invited to submit ideas or solutions via the platform's internet-based interface. Having completed the scouting phase, promising solutions and respective external knowledge holders are invited for an on-site presentation. During this second phase, external actors present their ideas to a pre-selected audience consisting of managers, team leaders, and experts of Jupiter positioned in business units relevant to the presented topics. Following up presentations, informal discussions between experts of Jupiter and external actors take place. During these informal conversations, application possibilities of external solutions are discovered. Phase 2 ends with the selection of promising external solutions for a pre-integration period of 100 days. The selection of promising external solutions is based on (a) the experts' evaluations of fit between Jupiter's internal product and process strategy and the suggested solution, and (b) the fit between the demands of the external knowledge holder and Jupiter's resources. During the pre-integration period of phase 3, the selected external actors closely cooperate with experts of Jupiter to discover applications of the external knowledge and to prepare integration. At the end of the pre-integration period, experts of Jupiter decide upon final integration. Reaching a positive conclusion, an investment, inlicensing, or cooperation contract will be realized in phase 4 .

Jupiter's project teams were formed on basis of the best fit of internal experts partially across departments. In case 1 (Table 1) the project team consisted of nine members from three different departments. As the project was concerned with an innovative user interface for robotic production systems, both, IT as well as production specialists were internally recruited for the project. The project team was led by a team leader responsible for a production facility. In case 2 (vehicle navigation software), the project team consisted of seven members from one department responsible for navigation. The background of the project members was IT and User-Interaction (UX) and was led by an innovation manager. In case 3 (trip planning software for electric vehicle charging), the project team consisted of four members from two departments responsible for navigation and in-car services. The background of the project members was IT and was led by a manager responsible for service integration. In case 4 (cashless parking solution), the project team consisted of four members from one department responsible for strategy. The background of the project members was engineering. No project leader was appointed.

\section{Analysis of main barriers during the phase of external knowledge integration}

Five overarching themes which constitute factors that either prevented or hampered the integration of external knowledge emerged from the analysis of the cases: (1) a lack of internal commitment and support, (2) negative attitudes towards external knowledge, (3) cooperation and communication problems with external partners, (4) coupling mismatches between internal and external knowledge and, (5) strategic orientation. 
The first type of barrier that emerged from the expert interviews was a lack of internal commitment and support in integrating external knowledge. As at the end of phase 2, experts of Jupiter decide upon a pre-integration period, they transfer the external knowledge to their respective departments. At this stage, a project team is established which examines integration possibilities in exchange with various departments and across different hierarchical levels. Here, a lack of internal commitment and support resulted from mainly two different aspects: an insufficient preparation of integration and an undefined integration process. Insufficient preparation of integration can be traced back, as in the third case, to missing information such as technical aspects, customer relevance, or preliminary economics analysis. Because gaining internal commitment requires information about the external knowledge to be presented at a glance, e.g., by means of a business case or market research analysis.

"We presented a detailed formulation of the technical aspects and various application use cases to the steering committee. But they were more interested in the numbers than the technical aspects like how much is it, what are the licensing cost per vehicle, where is the break-even?". ([19], IT scientist, Case 3)

Additionally, the absence of a formalized integration process in respective departments hampers the formation of a cross-department project team at an early stage. Therefore, role conflicts and undefined responsibilities hinder the exploration of application possibilities of external knowledge.

"The roles have not been clear at the beginning of the project. [...] We had

a hard time explaining procurement that we are not doing their job”. ([22],

Engineer, Case 4)

Further reasons that caused unwillingness of internal support observed during the analysis were a lack of hierarchical power, financial constraints, and negative former experiences with external knowledge.

The second thematic barrier which emerged from the case analysis is negative attitudes towards external knowledge-referred to as the NIH syndrome. Especially in the first case, strong resistance towards the external technology led to severe problems because several involved employees refused to collaborate with the external partner. In this regard, information has been restrained and communication with the external partner has been aborted to sabotage the integration process.

"These people [external partner] are mostly engineers and not IT scientists. Engineers know how to build cars, but not how to program interfaces". ([8], IT Scientist, Case 1)

It also emerged that an NIH attitude of employees was revealed in various and often more indirect behavioral reactions. That is, the negative attitude towards the external knowledge holder was repacked into arguments that apparently question the benefit of external knowledge per se instead of directly arguing against the external knowledge holder. 
"What I hear a lot, especially in a situation where new ideas enter the room that came from even outside that particular building, is that questions are raised like: can we even handle that? is it save? what are we paid for anyway? And I know it's not about that they can't, they just don't want". ([12] Innovation Manager, Case 2)

Additionally, during the analysis, it was observed that although employees who show no negative attitudes prior to the integration can become skeptical about external knowledge and develop an NIH attitude. Especially in case 3, where cooperation with the external partner was problematic, the emergence of an NIH attitude was observed.

"I was eager about the integration at the beginning but the cooperation was really disappointing and I learned that we at [Jupiter] built the best cars for a reason”. ([19], IT Scientist, Case 3)

But even in the absence of negative attitudes, cooperation problems with external partners can emerge that hamper the integration process. This third thematic barrier mainly appeared in the third case. Here, the external partner rejected face-to-face meetings due to travel costs and suggested phone calls and online meetings instead.

"Coordination with them was really problematic. Often, I had to write a second email to remind them to answer the first one. And I rarely got a call back". ([18], Team Leader, Case 3)

Also, the willingness of external actors to modify their ideas or technologies to make them applicable and remove the "stickiness" is a key requirement during the integration process (von Hippel 1994; Weissenberger-Eibl 2018). The reluctance of external partners to make modifications, therefore, compromises integration success. The fourth thematic barrier constitutes the incompatibility of internal and external knowledge. Even when the application of external knowledge seems promising at the beginning of a cooperation, incompatibility can turn out during the integration phase. For example, in the third case, integration mainly failed due to the coupling mismatch between internal and external knowledge.

"It just turned out that it was not possible. We modified, they modified, back and forth, but we did not recognized a performance improvement". ([17], Manager, Case 3)

The second aspect of this barrier is the adaptability of external knowledge. In the first case examined, the application of the external technology was fixed to one situation (use case). This increases the dependency on the external partner and leads to dissatisfaction with the external technology and integration failure.

The fifth thematic barrier refers to the strategic orientation of the firm. In-licensing models and temporary exclusive rights of external technologies are often not sufficient to reach a competitive advantage. Also, trust in the external partner emerged as a vital component of successful cooperation, especially in situations where critical data are exchanged. Table 3 provides an overview of the thematic barriers and representative quotations from expert interviews. 


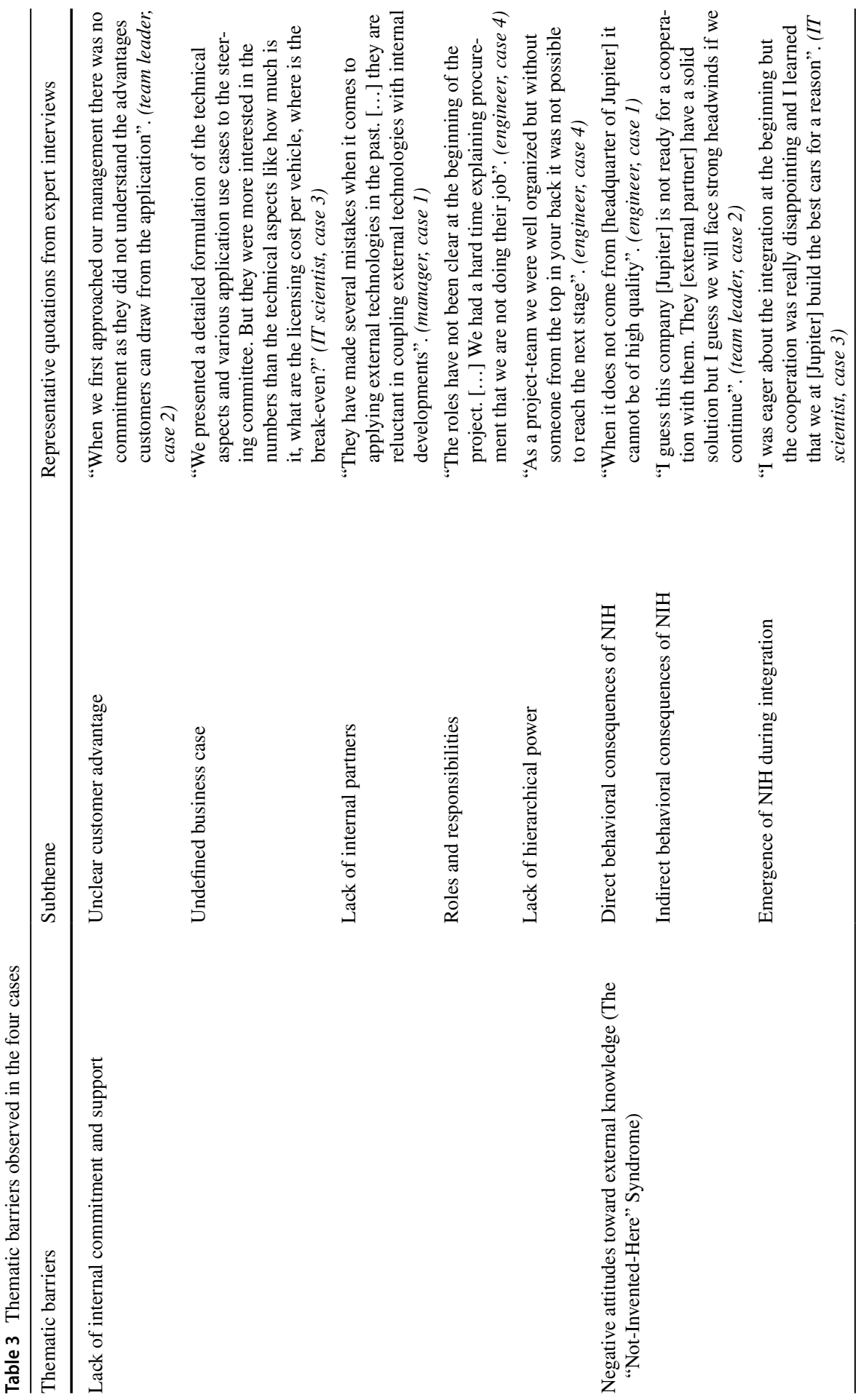




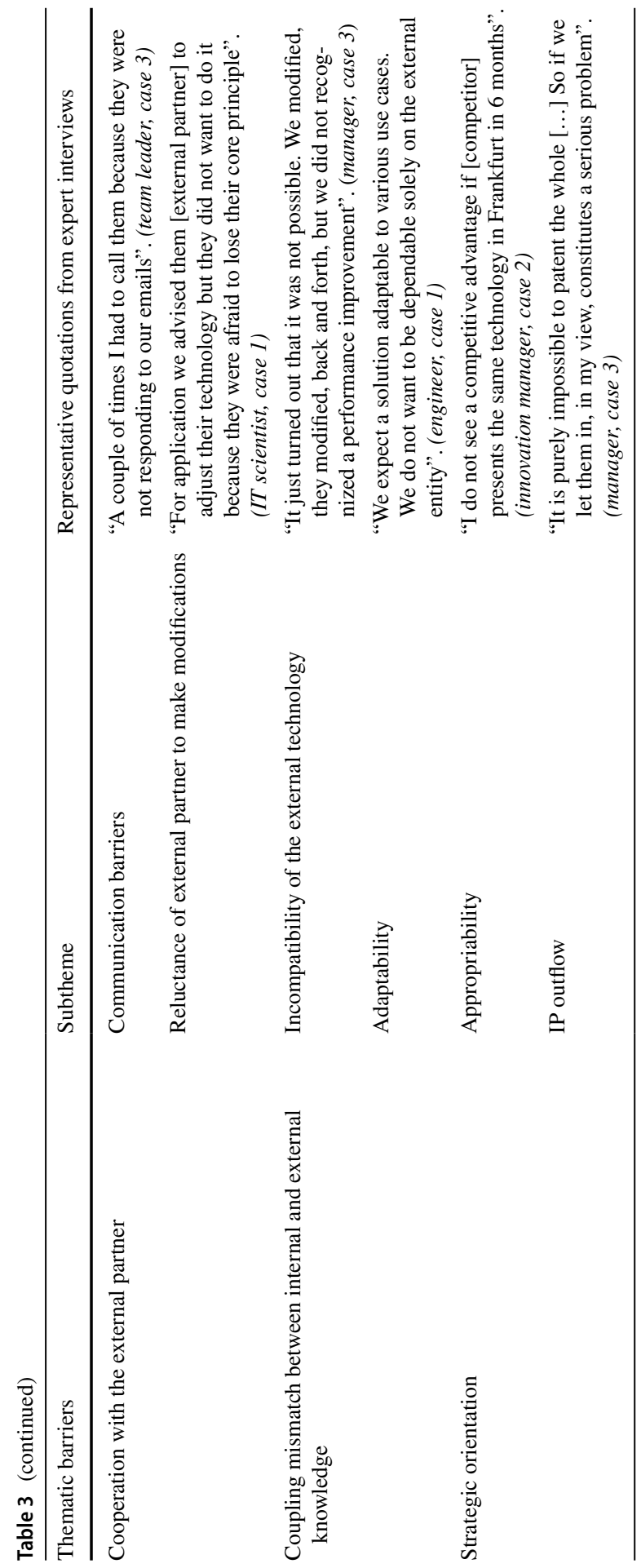

SN Business \& Economics 


\section{Contrasting cases and analysis of success factors}

While the thematic barriers which emerged from the interview analysis of case 1 and 3 should highlight obstacles emerging during the transfer of external knowledge from OI platforms, a contrasting analysis with two successfully integrated cases ( 2 and 4 ) should demonstrate how project teams developed interventions to remove these obstacles. Contrasting successful and unsuccessful cases, four thematic success factors became evident, namely: (1) gaining internal commitment and support, (2) attitude change toward external knowledge, (3) managing the cooperation with the external partner and, (4) support of the OI platform and the OI program.

In aggregate terms, the NIH syndrome and a lack of top management support and commitment have been the main reason for integration failure in the observed cases. Especially in the cases where the integration of external knowledge succeeded, interventions emerged from the analysis which particularly relieved these barriers. Four sub-factors to gain internal support became evident through the case analysis. First, successfully integrated cases developed a fine-grained integration strategy with the external partner containing information about possible application scenarios, a clear customer benefit, and economic analysis. This document served as a foundation for the cooperation as well as to inform the management about the cooperation. Second, the development of a dedicated integration process ensured to comply with internal standards. This department-internal process served as a first quality gate before the invention entered the formal innovation process (Cooper and Kleinschmidt 1993). Thereby, the idea or technology, whether stemming from an internal or external source has to meet certain "must have" criteria such as a clear customer need, a proof of concept, and an application scenario. Third, a clear customer need for the innovation has turned out to be the critical factor concerning the first go or no-go decision. Demonstrating the customer value precisely in both successful cases served as a key success factor to overcome initial resistance. Fourth, once top management commitment has been attained, demonstrating this support positively influences decision-making in the subsequent decision-making process.

"[...] and you can get them on your side by focusing on the factors that matter. I always ask two questions before every project: will it benefit the customer and can we earn more than it costs. And then I present only one slide with a preliminary answer concerning those two questions. From my experience, they [management] are less fascinated by the technical details but more by the story they [management] can tell about how we improve our brand." ([21], Team leader, Case 4)

Furthermore, several critical incidents were encountered that referred entirely to the NIH syndrome. While in case 1 and 3 negative attitudes towards external knowledge has been taken for granted, in case 2 and 4 two interventions of the project teams showed a positive effect in reducing NIH tendencies.

The first intervention was observed in case 2. Here, it was found that combining external and internal knowledge at an early stage reduces the negative attitudes 
toward external knowledge among stakeholders and decision-makers. The combination of external and internal knowledge in the actual case study appeared in the form of a minimum viable product (MVP), where internal developments have been coupled with the external technology to demonstrate the operating principle and the customer value. This combination gave the external knowledge a "local feel" and reduced initially negative attitudes.

"[...] it was just a box but with our latest head unit inside but when they saw how it works in combination with our products, they realized the potential we can draw from the external idea”. ([13], Team leader, Case 2)

The second intervention was observed in case 4 . While the project team was confronted with skepticism about the external knowledge due to a lack of trustworthiness in the external partner in a first decision round, an on-site meeting with the external partner was arranged with the managers of Jupiter. Here, a positive contact situation between the management team of Jupiter and the external partner led to a reduction of prejudices and a more positive evaluation of the external technology. Importantly, making it possible to ask specific questions to the external partner directly and agreeing on a "common goal" created trust and acceptance towards the external knowledge.

"The invitation for a workshop with our management-team was the best thing we could do for two reasons: First, they [external partner] could answer questions first hand and second, we finally got a decision on how to proceed with the project”. ([21], Team leader, Case 4)

Two further thematic success factors became evident during the analysis. The first one refers to the management of the cooperation with external knowledge holders. As external knowledge was sourced via Jupiter's OI platform in phase 1 and promising external ideas and technologies were selected in phase 2, a pre-integration period of 100 days started in phase 3. At this point, experts of Jupiter transfer the external solution to their respective departments and prepare the integration. Here, problems of communication and coordination with the external partner at the beginning of the project can hamper integration success. Success factors for providing the foundation of an effective and efficient cooperation between internal and external partners included a detailed cooperation plan as well as fast and reliable communication. Regarding a cooperation plan, a preliminary workshop with the external partner and internal stakeholders are one example of how to set up a common strategy for integration preliminary to further stage-gates. Also, physical proximity between internal and external partners proved to be crucial to quickly adopt changes and to conduct face-to-face meetings.

The second one refers to the OI platform and program itself. Here, interview participants highlighted that Jupiter benefited from the external knowledge, whether it was successfully integrated or not. That is, they agreed that the presented ideas or technologies were relevant for the problem at hand and, although in case 1 and 3 the integration failed, Jupiter benefited from the external perspectives as they 
fueled internal problem-solving. Furthermore, in successfully integrated cases, it was emphasized, that the four-phase process under the umbrella of the platform's appearance supported the integration. While the involvement of experts of Jupiter in the selection of external ideas and technologies supported the selection of relevant ideas in phase 2 , the 100-day pilot phase in phase 3 created a formal framework for experimentation with the external knowledge. The formalized nature of the pilot phase helped projects to gain a certain degree of relevance in the eyes of the top management and other internal stakeholders. In addition, the OI team assisted with legal and administrative issues to reduce the bureaucratic barriers of integration.

"Starting a pilot phase means that the external startup has overcome the first hurdle and an internal commission has them assessed as relevant. This also strengthens the relevancy in the eyes of decision-makers." ([21], Team leader, Case 4)

Table 4 provides an overview of the thematic success factors and representative quotations from expert interviews.

\section{Discussion, implications and conclusion}

\section{Discussion}

OI platforms are increasingly set up to benefit a firm's absorptive capabilities (Devece et al. 2019; Hilbolling et al. 2020). In this regard, they are a promising means to attract external knowledge (ideas, technologies) and to create a pool of valuable external knowledge potentially applicable for internal problem-solving (Rosenkopf and Nerkar 2001; Ter Wal et al. 2017; Weissenberger-Eibl 2018b). However, as platforms are instrumental by their very nature it became apparent that the contribution of OI platforms is limited to the early phases of the integration process. For firms to benefit from OI, attracted external knowledge has to be processed (i.e. assimilated, transformed, and exploited) by the individual members of the firm to make it applicable to commercial ends (Zahra and George 2002; Zahay et al. 2017). As external knowledge is usually integrated on the project level (Midler et al. 2016; Pellizzoni et al. 2019), the successful integration requires project teams to couple external knowledge with internal expertise to develop new knowledge connections, often incorporated in product-, process-, or service innovations (Baron 2006; Maier and Brem 2018). Here, previous literature has pointed to the fact that the process of external knowledge integration is rarely linear but contains much of what is called "trial and error" (Teece 2012; Brunswicker and Vanhaverbeke 2015). Additionally, previous research has identified project-level barriers that hamper the integration of external knowledge such as knowledge stickiness and negative attitudes towards external knowledge. (Katz and Allen 1982; von Hippel 1994; Lichtenthaler and Ernst 2006). As these barriers were described on a rather broad level, the underlying study specifically investigated the nature of these and other barriers on the level of projects to make them more tangible and to derive specific interventions. 


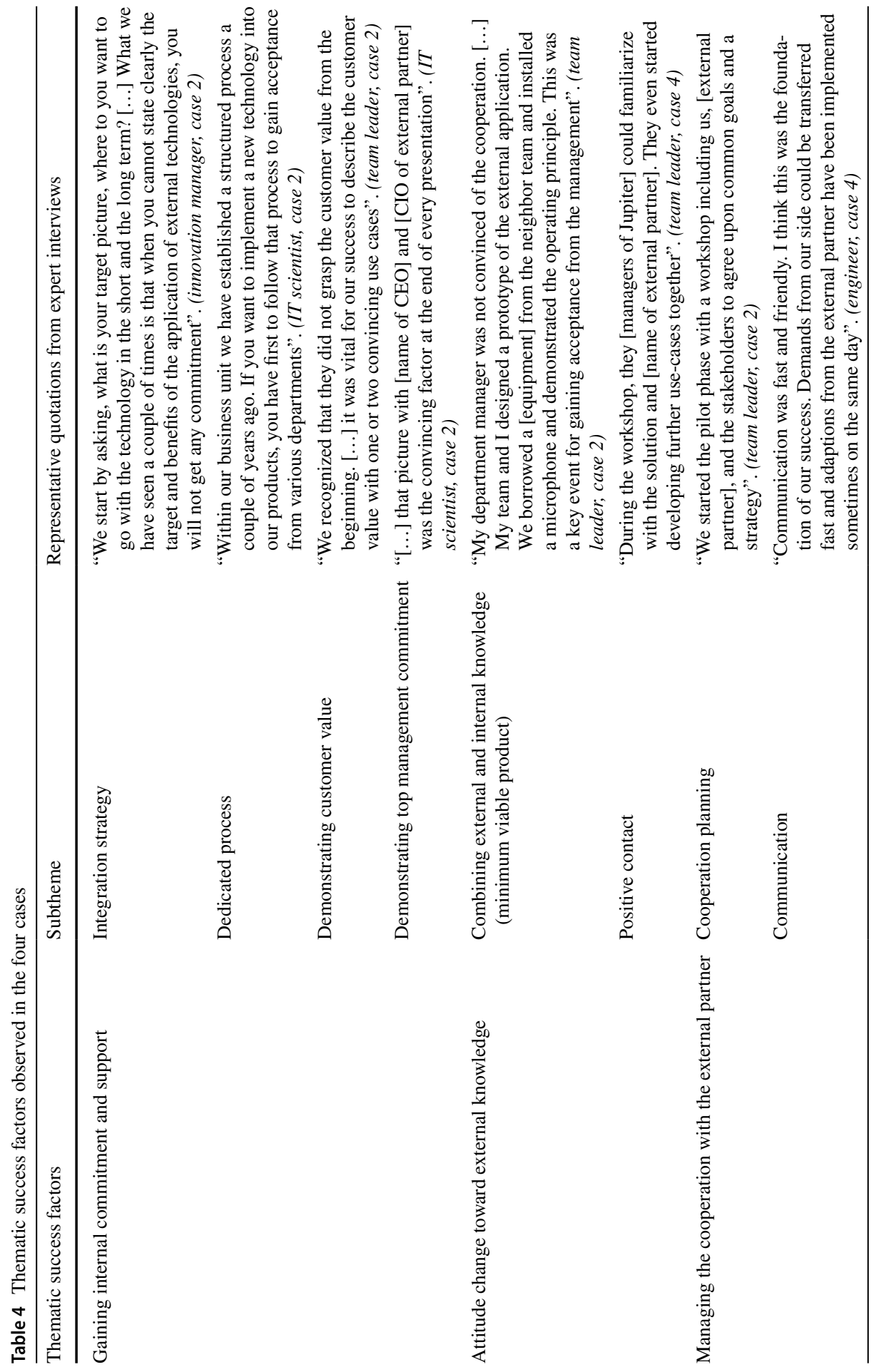

SN Business \& Economics 


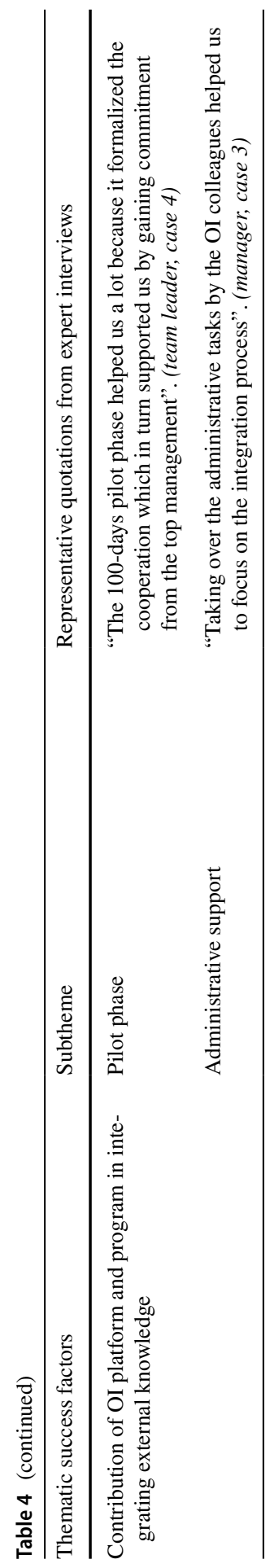


Contrasting multiple cases of projects integrating external knowledge from a firm-owned OI platform, the overarching theme that emerged through the case analysis which hampered the integration process referred to a lack of internal commitment and support. Although this barrier has been acknowledged by previous literature in the area of innovation management (Lüttgens et al. 2014; Sandberg and Aarikka-Stenroos 2014), the case analysis revealed various sub-themes possibly initiating this barrier. On a broad level, a lack of internal commitment and support can be traced back to the barrier of ability which is related to a lack of expertise within a specific domain, or the barrier of will which is related to a general resistance against change and innovation (Gemünden et al. 2007; Lüttgens et al. 2014). Regarding the barrier of ability, project teams have to make an additional effort to prepare for the integration. Due to the external nature of the knowledge, it often deviates from firm internal standards, language and routines (von Hippel 1994; Cassiman and Veugelers 2006; Foss et al. 2013). In this regard, the case analysis revealed that knowledge stickiness may appear in two different forms: stickiness with regard to the (technical) language new and distant knowledge is packed-in and stickiness with regard to physical (technological) requirements. As external knowledge holders usually develop their distinct way of presenting and transferring their ideas (Monteiro and Birkinshaw 2017), external knowledge sourced from OI platforms has to be translated to internal norms and standards by project teams in a first step to gain stakeholder acceptance. Here, a contrasting of cases showed that project teams presenting a detailed integration strategy and demonstrated the customer value could overcome a lack of ability among managers and decision-makers. In particular, by focusing on economic terms (e.g. conducting market research or economic analysis) prior to discussing technical matters, project teams could manage to overcome initial resistance. Furthermore, demonstrating the commitment of key individuals once obtained (e.g. top-management support) by means of a record or protocol in subsequent decision rounds showed a positive effect on gaining the acceptance of internal stakeholders. To overcome the physical stickiness, both, internal projects teams and external knowledge holders have to take into account process and technology-related adjustments. In case 2 for example, a member of Jupiter stayed on side of the external knowledge provider for more than ten days to cope with technology-related challenges. The direct (face-to-face) communication enabled ad hoc problem solving and the development of a minimum-viable product to demonstrate technology readiness, known as an antecedent of technology adoption (Lin et al. 2007; Walczuch et al. 2007; Hampel and Sassenberg 2021).

However, even in situations when the external input is economically beneficial for the focal firm, negative attitudes towards external knowledge-the NIH syndrome - may lead to a rejection of external knowledge (Katz and Allen 1982; Lichtenthaler and Ernst 2006; Hannen et al. 2019). Although the NIH syndrome is a highly cited problem during the transfer of external knowledge, research on interventions to counteract NIH remains scarce (Antons and Piller 2015; Hannen et al. 2019). While so far evidence for NIH is primarily anecdotal (Agrawal et al. 2010), the underlying study directly observed NIH tendencies by asking participants to take a third-person perspective as suggested by Burcharth (2014). In the context of the underlying cases, NIH was mainly triggered by the ego-defensive 
function of the attitude (Ajzen 2001). Suggesting an external solution or technology, internal experts and decision-makers either rejected or depreciated the external knowledge to defend their expert status. NIH even led to integration failure because individuals actively sabotaged the cooperation by restraining information and refusing communication with the external partner. To overcome NIH, especially among decision-makers, this study found two promising interventions with the potential to reduce negative attitudes towards external knowledge. First, it was found that "internalizing" external knowledge at an early stage by combining internal and external knowledge reduces NIH tendencies among decision-makers. More specifically, project teams will need to make a "marriage of materials"-an effort to repackage external knowledge to give it a local feel (Ter Wal et al. 2017). This can be archived by either presenting possible application scenarios showing how external solutions might benefit products or services in combination with internal knowledge or by demonstrating initial product expressions or operating principles (e.g. by means of a minimum viable product). Second, it was observed that creating a positive contact situation between internal colleagues and external knowledge holders led to a better evaluation of the external knowledge after the contact situation. Research in social psychology shows that positive contact between groups led to reduced discrimination and attitude change (Brewer and Miller 1988; Brown and Hewstone 2005). That is because the personal acquaintances between group members result in a stronger salience of personal characteristics and a decreased perception of group boundaries (Hewstone 2000; Tropp and Pettigrew 2016). Therefore, creating a situation where decision-makers can encounter external knowledge directly through the external knowledge holder (e.g. during a workshop) has the potential to change negative attitudes towards external knowledge among individuals affected by the NIH syndrome.

Also, bureaucratic and administrative barriers can hamper the integration process. Here, due to assisting with legal and administrative tasks by a dedicated OI team, bureaucratic-related barriers can be removed from individuals who take over the external knowledge integration role. Additionally, in the case of Jupiter, the implementation of a 100-day pilot phase under the umbrella of the platforms' appearance paved the way for external knowledge assimilation by providing a "safe space" that allows internal colleagues to analyze and understand the external knowledge in depth.

Finally, in successfully integrated cases, it was observed that alliances with key individuals have been formed whose involvement became a key success factor during the integration process. In this vein, the promotor model suggests that the combination of a power promotor (individual with hierarchical power) and a technology promotor (individual with technological know-how) is required to overcome organizational rigidity and resistance. In situations of a growing number of internal stakeholders, the additional involvement of a process promoter (individual with organizational know-how) can support the communication and alignment of involved persons (Hauschildt and Kirchmann 2001; Klein and Knight 2005; Gemünden et al. 2007). In this sense, the individuals who participated in the selection of promising external partners and decided upon a pre-integration phase can be regarded as technology promotors. As they have a vast interest in 
integration, they already gained a sufficient technological understanding of the external knowledge. However, especially in the observed cases where the integration failed, individuals faced severe problems of forming a project team and gaining cross-departmental acceptance due to a lack of hierarchical power and support (power promotor). Therefore, the study highlights the need of forming alliances, especially with individuals who bear a certain degree of hierarchical power, early in the process of external knowledge integration.

\section{Theoretical contribution}

The effectiveness of OI in general and OI platforms, in particular, have recently been questioned by the academic literature (Bayus 2012; von Briel and Recker 2017; Andersen and Gadde 2019). However, to address these concerns, a better multilevel understanding of OI becomes necessary. The study contributes to the literature on OI the organizational factors that hamper or impede the successful integration of external knowledge within an established multinational corporation. As previous research states that firm's often face difficulties in effectively implementing OI measures (Hienerth and Lettl 2011; Brunswicker and Chesbrough 2018), this barriers approach should raise the awareness of the challenges managers and project teams face when integrating external knowledge from an OI platform. While previous research has strongly focused on the theoretical development of OI at the level of the organization (Bogers et al. 2017), the current study contributes to a multilevel understanding of OI by including the project-level perspective (Foege et al. 2019). Specifically, five thematic barriers on the project level which might prevent a successful integration of external knowledge and ideas have been identified. Unlike conducting purely internal projects, where a dedicated stage-gate process formalizes project planning and execution (Cooper 1990; Lakemond et al. 2016), an additional effort for project teams arises from the internalization of external expertise to make it applicable. Hence, an effort of establishing additional routines (e.g. experimentation, communication, contact) with internal and external sources becomes necessary to gain internal commitment and support. Additionally, the study highlights the profound role of key individuals during the integration process whose involvement becomes necessary to prepare organizations for integrating external knowledge. (Hauschildt and Kirchmann 2001; Henkel 2009).

Furthermore, the study contributes to the emerging discussion on how to cure the NIH syndrome of affected employees (Antons et al. 2017; Hannen et al. 2019). While research on the NIH syndrome itself remains scarce, the underlying study directly observed NIH tendencies by asking participants to take a third-person perspective (Burcharth et al. 2014). A view on the NIH syndrome through a social psychology lens gives reason to assume that in particular project teams of longstanding and stable composition have the tendency to reject external knowledge to maintain a positive social identity (Tajfel 1974; Turner et al. 1979). In particular, external knowledge might induce a social identity threat when external actors demonstrate a viable solution with the potential for internal application. This assumption is supported by research in the area of $R \& D$ management which shows that the 
more similar an external source is considered from the perspective of an internal project team (e.g. a horizontal competitor), the less knowledge is utilized from these sources (Hussinger and Wastyn 2016). Therefore, the intervention of positive contact between internal and external knowledge holders observed during the analysis phase of the cases built on the social identity view. Through, for example, the possibility of personal contact (e.g. during a workshop) stereotypes could be reduced by increasing the salience of the personal characteristics of external knowledge holders and reducing the salience of the group memberships (Sherif 1958; Brewer et al. 1984; Hewstone 2000).

\section{Practical implications}

Project teams and respective managers have to be aware of organizational opposition when integrating external knowledge. Due to the external nature of the knowledge, the NIH syndrome among decision-makers can lead to a devaluation or rejection of external ideas or technologies (Lichtenthaler and Ernst 2006; Antons and Piller 2015). Also, external knowledge may not be easily transferable to other firms as it is often sticky to the context where it was first developed. (von Hippel 1994; Schwenk and Weissenberger-Eibl 2009; Ter Wal et al. 2017). Additionally, inflexibility and reluctance of external partners in adapting their solutions to internal requirements as well as the absence of communication routines can lead to integration failure.

Three pieces of advice for project teams and respective managers seeking to successfully integrate external knowledge can be derived from the research. First, to prevent the occurrence of the NIH syndrome, external knowledge has to be combined with internal knowledge at an early stage of the integration process and in the apron of decision-making. This may be achieved by means of simulations, presentations, or prototypes showing how external knowledge works in combination with internal expertise. Additionally, creating a positive contact situation between internal experts and external knowledge holders (e.g. during a workshop) can benefit a trustful climate between involved parties and reduce caveats concerning external solutions. Second, to remove the stickiness of external knowledge, it has to be acknowledged that external knowledge integration is rather a process than an act. Therefore, establishing communication routines with the external partner prior to the start of the process accelerates mutual trust and learning. Third, promotors and innovation champions contribute to relieving internal barriers and resistance toward external knowledge integration by focusing on their specific roles. Meaning, that dedicated project members take over responsibility and action for their very roles in the integration process (e.g. communication experts, technical experts, structuring and planning experts).

\section{Limitations and further research}

The methodological approach of the study brings along a number of limitations which simultaneously provide a starting point for future research. First, a multiplecase study design within a single corporation was chosen for the empirical part. 
While it captured a rich perspective of the barriers that hamper external knowledge integration, the results should be interpreted in front of the background of the single firm view which did not aim for statistical saturation. Instead, the study's goal was to present indications of how organizational barriers can be overcome to successfully integrate outside knowledge within a large organization. To further strengthen the generalizability of the findings, additional qualitative and quantitative studies are hence needed. Qualitative studies in other industries such as the service sector could further shed light on non-technical challenges when integrating ideas from external sources. Also, the explored success factors of the underlying study could be transferred to correlative designs to test for their explanatory power. Second, the present study focused on a large multinational corporation within the automotive industry. Additional investigations of SMEs could examine the questions of how OI is put into practice and which specific barriers hamper external knowledge integration within SME's. Third, the present study investigated the barriers and success factors of external knowledge integration from the perspective of the receiving organization. To further strengthen these results, future research could include the perspective of external actors by means of a qualitative approach. Fourth, the study observed the NIH syndrome as a major barrier in the process of external knowledge integration. Beyond the two suggested countermeasures, future research should specifically focus on developing interventions to cure the NIH syndrome. Here, research in social psychology on interventions to reduce intergroup-conflicts such as the Common-Ingroup-Identity-Model (Gaertner et al. 1993; Crisp et al. 2006) or the Superordinate-Goals-Framework (Sherif 1958; Gaertner et al. 2000) are promising directions to derive and test interventions to change negative attitudes towards external knowledge directly.

\section{Conclusion}

Organizations often fail in adopting OI activities (Hienerth and Lettl 2011; Brunswicker and Chesbrough 2018). The implementation of an OI platform to identify and source external knowledge does not guarantee OI success (von Hippel 1994). After potentially valuable external knowledge has been identified, it has to be sized, hence, resources have to be mobilized to integrate external ideas or technologies into a firm's innovation process (Teece 2012). Here, the project level becomes increasingly important as integration is typically carried out in the form of projects that aim to combine internal expertise with knowledge from external sources. Due to the external nature of the knowledge, project teams face organizational barriers that hamper or impede the integration process. Managers and project teams have to be aware of negative attitudes in form of the NIH syndrome which can lead to a devaluation of outside knowledge and result in a lack of organizational support. Also, external knowledge may not easily be transferable to internal standards and routines (von Hippel 1994; Herzog and Leker 2010) and cooperation with external knowledge holders may be problematic if insufficiently planned and prepared. However, the barriers approach to external knowledge integration should make managers 
and project teams aware of potential problems and, hence, should serve as a starting point in overcoming organizational opposition.

Supplementary Information The online version contains supplementary material available at https://oi. org/10.1007/s43546-021-00101-5.

Author contributions Author 1: 60\%; author 2: $40 \%$.

Funding Open Access funding enabled and organized by Projekt DEAL. Privately funded.

Availability of data and materials Included in text. The data used for the analysis are qualitative in nature (interviews and field notes). No quantitative dataset was generated and used for the study. If requested, further material (notes and/or quotes) from the interviews can be provided by the authors.

Code availability Not applicable.

\section{Declarations}

Conflict of interest The authors declare that they have no conflict of interest.

Open Access This article is licensed under a Creative Commons Attribution 4.0 International License, which permits use, sharing, adaptation, distribution and reproduction in any medium or format, as long as you give appropriate credit to the original author(s) and the source, provide a link to the Creative Commons licence, and indicate if changes were made. The images or other third party material in this article are included in the article's Creative Commons licence, unless indicated otherwise in a credit line to the material. If material is not included in the article's Creative Commons licence and your intended use is not permitted by statutory regulation or exceeds the permitted use, you will need to obtain permission directly from the copyright holder. To view a copy of this licence, visit http://creativecommons.org/licen ses/by/4.0/.

\section{References}

Agrawal A, Cockburn I, Rosell C (2010) Not invented here? Innovation in company towns. J Urban Econ 67:78-89. https://doi.org/10.1016/j.jue.2009.10.004

Ajzen I (2001) Nature and operation of attitudes. Annu Rev Psychol 52:27-58. https://doi.org/10.1146/ annurev.psych.52.1.27

Aken JEV (2005) Management research as a design science: articulating the research products of mode 2 knowledge production in management. Br J Manag 16:19-36. https://doi.org/10.1111/j.1467-8551. 2005.00437.x

Allen T, Katz R, Grady JJ, Slavin N (1988) Project team aging and performance: the roles of project and functional managers. RD Manag 18:295-308. https://doi.org/10.1111/j.1467-9310.1988.tb00605.x

Almirall E, Casadesus-Masanell R (2010) Open versus closed innovation: a model of discovery and divergence. Acad Manage Rev 35:27-47. https://doi.org/10.5465/amr.35.1.zok27

Andersen PH, Gadde L-E (2019) Organizational interfaces and innovation: the challenge of integrating supplier knowledge in LEGO systems. J Purch Supply Manag 25:18-29. https://doi.org/10.1016/j. pursup.2018.08.002

Antons D, Piller FT (2015) Opening the black box of "not invented here": attitudes, decision biases, and behavioral consequences. Acad Manag Perspect 29:193-217. https://doi.org/10.5465/amp.2013. 0091

Antons D, Declerck M, Diener K et al (2017) Assessing the not-invented-here syndrome: development and validation of implicit and explicit measurements. J Organ Behav 38:1227-1245. https://doi. org/10.1002/job.2199 
Arora A, Gambardella A (2010) Ideas for rent: an overview of markets for technology. Ind Corp Change 19:775-803. https://doi.org/10.1093/icc/dtq022

Baron RA (2006) Opportunity recognition as pattern recognition: How entrepreneurs "connect the dots" to identify new business opportunities. Acad Manag Perspect 20:104-119. https://doi.org/10.5465/ amp.2006.19873412

Bayus BL (2012) Crowdsourcing new product ideas over time: an analysis of the dell IdeaStorm community. Manag Sci 59:226-244. https://doi.org/10.1287/mnsc.1120.1599

Birkinshaw J, Ridderstråle J (1999) Fighting the corporate immune system: a process study of subsidiary initiatives in multinational corporations. Int Bus Rev 8:149-180. https://doi.org/10.1016/S09695931(98)00043-2

Bogers M, Zobel A-K, Afuah A et al (2017) The open innovation research landscape: established perspectives and emerging themes across different levels of analysis. Ind Innov 24:8-40. https://doi. org/10.1080/13662716.2016.1240068

Bogers M, Chesbrough H, Moedas C (2018a) Open innovation: research, practices, and policies. Calif Manage Rev 60:5-16. https://doi.org/10.1177/0008125617745086

Bogers M, Foss NJ, Lyngsie J (2018b) The "human side" of open innovation: the role of employee diversity in firm-level openness. Res Policy 47:218-231. https://doi.org/10.1016/j.respol.2017.10.012

Braun V, Clarke V (2006) Using thematic analysis in psychology. Qual Res Psychol 3:77-101. https://doi. org/10.1191/1478088706qp063oa

Brewer MB, Miller N (1988) Contact and Cooperation. In: Katz PA, Taylor DA (eds) Eliminating Racism: profiles in controversy. Springer US, Boston, pp 315-326

Brewer MB, Miller N, Brewer MB et al (1984) Beyond the contact hypothesis: theoretical perspectives on desegregation. Elsevier

Brown R, Hewstone M (2005) An integrative theory of intergroup contact. Advances in experimental social psychology, vol 37. Elsevier Academic Press, San Diego, pp 255-343

Brunswicker S, Chesbrough H (2018) The adoption of open innovation in large firms. Res-Technol Manag 61:35-45. https://doi.org/10.1080/08956308.2018.1399022

Brunswicker S, Vanhaverbeke W (2015) Open innovation in Small and Medium-Sized Enterprises (SMEs): external knowledge sourcing strategies and internal organizational facilitators. J Small Bus Manag 53:1241-1263. https://doi.org/10.1111/jsbm.12120

Burcharth ALA, Knudsen MP, Søndergaard HA (2014) Neither invented nor shared here: the impact and management of attitudes for the adoption of open innovation practices. Technovation 34:149-161. https://doi.org/10.1016/j.technovation.2013.11.007

Cassiman B, Veugelers R (2006) In search of complementarity in innovation strategy: internal R\&D and external knowledge acquisition. Manag Sci 52:68-82

Cheng CJ, Huizingh K (2014) When is open innovation beneficial? The role of strategic orientation. J Prod Innov Manag 31:1235-1253. https://doi.org/10.1111/jpim.12148

Chesbrough HW (2003) The era of open innovation. MIT Sloan Manag Rev 44:35-41

Chesbrough H (2004) Managing open innovation. Res-Technol Manag 47:23-26. https://doi.org/10.1080/ 08956308.2004 .11671604

Chesbrough HW (2006) Open innovation : a new paradigm for understanding industrial innovation. Open Innov Res New Paradigm 400:0-19

Chiaroni D, Chiesa V, Frattini F (2010) Unravelling the process from Closed to Open Innovation: evidence from mature, asset-intensive industries. RD Manag 40:222-245. https://doi.org/10.1111/j. 1467-9310.2010.00589.x

Cohen WM, Levinthal DA (1990) Absorptive capacity: a new perspective on learning and innovation. Adm Sci Q 35:128-152. https://doi.org/10.2307/2393553

Cooper RG (1990) Stage-gate systems: a new tool for managing new products. Bus Horiz 33:44-54. https://doi.org/10.1016/0007-6813(90)90040-I

Cooper RG, Kleinschmidt EJ (1993) Screening new products for potential winners. Long Range Plann 26:74-81. https://doi.org/10.1016/0024-6301(93)90208-W

Creswell JW (2012) Qualitative inquiry and research design, 3rd edn. Sage Publications, Los Angeles (London New Dehli Singapore Washington DC)

Crisp RJ, Stone CH, Hall NR (2006) Recategorization and subgroup identification: predicting and preventing threats from common ingroups. Pers Soc Psychol Bull 32:230-243. https://doi.org/10. $1177 / 0146167205280908$ 
Cruz-Ros S, Guerrero-Sánchez DL, Miquel-Romero M-J (2018) Absorptive capacity and its impact on innovation and performance: findings from SEM and fsQCA. Rev Manag Sci. https://doi.org/10. 1007/s11846-018-0319-7

Dahlander L, Frederiksen L (2011) The core and cosmopolitans: a relational view of innovation in user communities. Organ Sci 23:988-1007. https://doi.org/10.1287/orsc.1110.0673

Devece C, Palacios-Marqués D, Ribeiro-Soriano DE (2019) IT-based strategy, capabilities, and practices: crowdsourcing implementation in market-oriented firms. Rev Manag Sci. https://doi.org/10.1007/ s11846-019-00369-w

Dillworth J, Dickson VV, Reyentovich A, Shedlin MG (2019) Patient decision-making regarding left ventricular assist devices: a multiple case study. Intensive Crit Care Nurs 51:7-14. https://doi.org/10. 1016/j.iccn.2018.10.004

Dyer JH, Singh H (1998) The relational view: cooperative strategy and sources of interorganizational competitive advantage. Acad Manage Rev 23:660-679. https://doi.org/10.2307/259056

Eisenhardt KM (1989) Building theories from case study research. Acad Manage Rev 14:532-550. https://doi.org/10.2307/258557

Enkel E, Gassmann O, Chesbrough H (2009) Open R\&D and open innovation: exploring the phenomenon. RD Manag 39:311-316. https://doi.org/10.1111/j.1467-9310.2009.00570.x

Foege JN, Lauritzen GD, Tietze F, Salge TO (2019) Reconceptualizing the paradox of openness: How solvers navigate sharing-protecting tensions in crowdsourcing. Res Policy. https://doi.org/10. 1016/j.respol.2019.01.013

Foss NJ, Lyngsie J, Zahra SA (2013) The role of external knowledge sources and organizational design in the process of opportunity exploitation. Strateg Manag J 34:1453-1471. https://doi.org/10.1002/ smj. 2135

Frey K, Lüthje C, Haag S (2011) Whom should firms attract to open innovation platforms? The role of knowledge diversity and motivation. Long Range Plann 44:397-420. https://doi.org/10.1016/j.lrp. 2011.09.006

Gaertner SL, Dovidio JF, Anastasio PA et al (1993) The common ingroup identity model: recategorization and the reduction of intergroup bias. Eur Rev Soc Psychol 4:1-26. https://doi.org/10.1080/ 14792779343000004

Gaertner SL, Dovidio JF, Banker BS et al (2000) Reducing intergroup conflict: from superordinate goals to decategorization, recategorization, and mutual differentiation. Group Dyn Theory Res Pract 4:98-114. https://doi.org/10.1037/1089-2699.4.1.98

Gassmann O (2006) Opening up the innovation process: towards an agenda. RD Manag 36:223-228. https://doi.org/10.1111/j.1467-9310.2006.00437.x

Gemünden HG, Salomo S, Hölzle K (2007) Role models for radical innovations in times of open innovation. Creat Innov Manag 16:408-421. https://doi.org/10.1111/j.1467-8691.2007.00451.x

Ghezzi A, Gabelloni D, Martini A, Natalicchio A (2018) Crowdsourcing: a review and suggestions for future research. Int J Manag Rev 20:343-363. https://doi.org/10.1111/ijmr.12135

Gibb A (2002) In pursuit of a new 'enterprise' and 'entrepreneurship' paradigm for learning: creative destruction, new values, new ways of doing things and new combinations of knowledge. Int $\mathbf{J}$ Manag Rev 4:233-269. https://doi.org/10.1111/1468-2370.00086

Hampel N, Sassenberg K (2021) Needs-oriented communication results in positive attitudes towards robotic technologies among blue-collar workers perceiving low job demands. Comput Hum Behav Rep 3:100086

Hannen J, Antons D, Piller F et al (2019) Containing the Not-Invented-Here Syndrome in external knowledge absorption and open innovation: the role of indirect countermeasures. Res Policy 48:103822. https://doi.org/10.1016/j.respol.2019.103822

Hargadon A, Fanelli A (2002) Action and possibility: reconciling dual perspectives of knowledge in organizations. Organ Sci 13:290-302. https://doi.org/10.1287/orsc.13.3.290.2772

Hauschildt J, Kirchmann E (2001) Teamwork for innovation-the 'troika' of promotors. RD Manag 31:41-49. https://doi.org/10.1111/1467-9310.00195

Henkel J (2009) Champions of revealing - the role of open source developers in commercial firms. Ind Corp Change 18:435-471. https://doi.org/10.1093/icc/dtn046

Herzog P, Leker J (2010) Open and closed innovation-different innovation cultures for different strategies. Int J Technol Manag 52:322-343. https://doi.org/10.1504/IJTM.2010.035979

Hewitt-Dundas N, Roper S (2017) Exploring market failures in open innovation. Int Small Bus J. https:// doi.org/10.1177/0266242617696347 
Hewstone M (2000) Contact and categorization: social psychological interventions to change intergroup relations. Stereotypes and prejudice: essential readings. Psychology Press, New York, pp 394-418

Hienerth C, Lettl C (2011) Exploring how peer communities enable lead user innovations to become standard equipment in the industry: community pull effects. J Prod Innov Manag 28:175-195. https://doi.org/10.1111/j.1540-5885.2011.00869.x

Hilbolling S, Berends H, Deken F, Tuertscher P (2020) Complementors as connectors: managing open innovation around digital product platforms. RD Manag 50:18-30. https://doi.org/10.1111/radm. 12371

Hossain M, Islam KMZ (2015) Ideation through online open innovation platform: dell ideastorm. J Knowl Econ 6:611-624. https://doi.org/10.1007/s13132-015-0262-7

Hussinger K, Wastyn A (2016) In search for the not-invented-here syndrome: the role of knowledge sources and firm success. RD Manag 46:945-957

Jansen JJP, Van Den Bosch FAJ, Volberda HW (2005) Managing potential and realized absorptive capacity: How do organizational antecedents matter? Acad Manage J 48:999-1015. https://doi.org/10. 5465/amj.2005.19573106

Jeppesen LB, Lakhani KR (2010) Marginality and problem-solving effectiveness in broadcast search. Organ Sci 21:1016-1033. https://doi.org/10.1287/orsc.1090.0491

Kathoefer DG, Leker J (2012) Knowledge transfer in academia: an exploratory study on the Not-InventedHere Syndrome. J Technol Transf 37:658-675. https://doi.org/10.1007/s10961-010-9204-5

Katila R, Ahuja G (2002) Something old, something new: a longitudinal study of search behavior and new product introduction. Acad Manage J 45:1183-1194. https://doi.org/10.2307/3069433

Katz R, Allen TJ (1982) Investigating the Not Invented Here (NIH) syndrome: a look at the performance, tenure, and communication patterns of $50 \mathrm{R} \&$ D Project Groups. RD Manag 12:7-20. https://doi. org/10.1111/j.1467-9310.1982.tb00478.x

Kim N, Kim D-J, Lee S (2015) Antecedents of open innovation at the project level: empirical analysis of Korean firms. R Manag 45:411-439. https://doi.org/10.1111/radm.12088

Klein KJ, Knight AP (2005) Innovation implementation: overcoming the challenge. Curr Dir Psychol Sci 14:243-246

Kostova T (1999) Transnational transfer of strategic organizational practices: a contextual perspective. Acad Manage Rev 24:308-324. https://doi.org/10.2307/259084

Kozinets RV, Hemetsberger A, Schau HJ (2008) The wisdom of consumer crowds: collective innovation in the age of networked marketing. J Macromarketing 28:339-354. https://doi.org/10.1177/02761 46708325382

Lakemond N, Bengtsson L, Laursen K, Tell F (2016) Match and manage: the use of knowledge matching and project management to integrate knowledge in collaborative inbound open innovation. Ind Corp Change 25:333-352. https://doi.org/10.1093/icc/dtw004

Larsen P, Lewis A (2007) How award-winning SMEs manage the barriers to innovation. Creat Innov Manag 16:142-151. https://doi.org/10.1111/j.1467-8691.2007.00428.x

Lauritzen GD, Karafyllia M (2019) Perspective: leveraging open innovation through paradox. J Prod Innov Manag 36:107-121. https://doi.org/10.1111/jpim.12474

Laursen K, Salter A (2006) Open for innovation: the role of openness in explaining innovation performance among U.K. manufacturing firms. Strateg Manag J 27:131-150. https://doi.org/10.1002/ smj.507

Leiponen A, Helfat CE (2010) Innovation objectives, knowledge sources, and the benefits of breadth. Strateg Manag J 31:224-236. https://doi.org/10.1002/smj.807

Lichtenthaler U, Ernst H (2006) Attitudes to externally organising knowledge management tasks: a review, reconsideration and extension of the NIH syndrome. RD Manag 36:367-386. https://doi. org/10.1111/j.1467-9310.2006.00443.x

Lin C-H, Shih H-Y, Sher PJ (2007) Integrating technology readiness into technology acceptance: the TRAM model. Psychol Mark 24:641-657. https://doi.org/10.1002/mar.20177

Lin C, Wu J-C, Yen DC (2012) Exploring barriers to knowledge flow at different knowledge management maturity stages. Inf Manage 49:10-23. https://doi.org/10.1016/j.im.2011.11.001

Lowik S, Kraaijenbrink J, Groen AJ (2017) Antecedents and effects of individual absorptive capacity: a micro-foundational perspective on open innovation. J Knowl Manag 21:1319-1341. https://doi.org/ 10.1108/JKM-09-2016-0410

Lüttgens D, Pollok P, Antons D, Piller F (2014) Wisdom of the crowd and capabilities of a few: internal success factors of crowdsourcing for innovation. J Bus Econ 84:339-374. https://doi.org/10.1007/ s11573-014-0723-7 
Maier MA, Brem A (2018) What innovation managers really do: a multiple-case investigation into the informal role profiles of innovation managers. Rev Manag Sci 12:1055-1080. https://doi.org/10. 1007/s11846-017-0238-z

Maxwell JA (2012) Qualitative research design: an interactive approach, 3rd edn. Sage Publications Ltd., Thousand Oaks

Mergel I, Desouza KC (2013) Implementing open innovation in the public sector: the case of challenge. gov. Public Adm Rev 73:882-890. https://doi.org/10.1111/puar.12141

Midler C, Killen CP, Kock A (2016) Project and innovation management: bridging contemporary trends in theory and practice. Proj Manag J 47:3-7. https://doi.org/10.1002/pmj.21587

Miles MB, Huberman AM (1994) Qualitative data analysis: an expanded sourcebook, 2nd edn. Sage Publications Ltd., Thousand Oaks

Miozzo M, Desyllas P, Lee H, Miles I (2016) Innovation collaboration and appropriability by knowledgeintensive business services firms. Res Policy 45:1337-1351. https://doi.org/10.1016/j.respol.2016. 03.018

Monteiro F, Birkinshaw J (2017) The external knowledge sourcing process in multinational corporations. Strateg Manag J 38:342-362. https://doi.org/10.1002/smj.2487

Monteiro F, Mol M, Birkinshaw J (2017) Ready to be open? Explaining the firm level barriers to benefiting from openness to external knowledge. Long Range Plann 50:282-295. https://doi.org/10. 1016/j.1rp.2015.12.008

Nelson RR, Winter SG (1990) An evolutionary theory of economic change. Harvard University Press, Cambridge (Reprint)

Nylund PA, Ferras-Hernandez X, Brem A (2020) Automating profitably together: Is there an impact of open innovation and automation on firm turnover? Rev Manag Sci 14:269-285. https://doi.org/10. 1007/s11846-018-0294-z

Ozkan NN (2015) An example of open innovation: P\&G. Procedia - Soc Behav Sci 195:1496-1502. https://doi.org/10.1016/j.sbspro.2015.06.450

Pablo D, Iammarino S, Savona M, von Tunzelmann N (2012) What hampers innovation? Revealed barriers versus deterring barriers. Res Policy 41:482-488

Pellizzoni E, Trabucchi D, Buganza T (2019) When agility meets open innovation: two approaches to manage inbound projects. Creat Innov Manag 28:464-476. https://doi.org/10.1111/caim.12337

Rosenkopf L, Nerkar A (2001) Beyond local search: boundary-spanning, exploration, and impact in the optical disk industry. Strateg Manag J 22:287-306. https://doi.org/10.1002/smj.160

Rothaermel FT, Hess AM (2007) Building dynamic capabilities: innovation driven by individual-, firm-, and network-level effects. Organ Sci 18:898-921. https://doi.org/10.1287/orsc.1070.0291

Salter A, Criscuolo P, Ter Wal ALJ (2014) Coping with open innovation: responding to the challenges of external engagement in R\&D. Calif Manage Rev 56:77-94. https://doi.org/10.1525/cmr.2014. 56.2 .77

Sandberg B, Aarikka-Stenroos L (2014) What makes it so difficult? A systematic review on barriers to radical innovation. Ind Mark Manag 43:1293-1305. https://doi.org/10.1016/j.indmarman.2014.08. 003

Sawhney M, Prandelli E, Verona G (2003) The Power of Innomediation-“Innomediaries" are helping companies innovate more effectively by connecting them over the Internet with a wide variety of current and potential customers. MIT Sloan Manag Rev 44(2):77

Schlagwein D, Bjorn-Andersen N (2014) Organizational learning with crowdsourcing: the revelatory case of LEGO. J Assoc Inf Syst. https://doi.org/10.17705/1jais.00380

Schwenk J, Weissenberger-Eibl M (2009) "Lifeblood knowledge": dynamic relational capabilities (DRC) and knowledge for firm innovativeness and competitive advantage. Meas Bus Excell 13:7-16. https://doi.org/10.1108/13683040910961162

Seus F, Weissenberger-Eibl MA, Zern-Breuer R (2020) Considering representational gaps-how subsidiaries' relationship affects multi-location project management. Int J Proj Organ Manag 12:321-345. https://doi.org/10.1504/IJPOM.2020.111068

Sherif M (1958) Superordinate goals in the reduction of intergroup conflict. Am J Sociol 63:349-356. https://doi.org/10.1086/222258

Stake RE (2005) Multiple case study analysis, New. Guilford Publications, New York

Stanko MA, Fisher GJ, Bogers M (2017) Under the wide umbrella of open innovation. J Prod Innov Manag 34:543-558. https://doi.org/10.1111/jpim.12392

Tajfel H (1974) Social identity and intergroup behaviour. Inf Int Soc Sci Counc 13:65-93. https://doi.org/ $10.1177 / 053901847401300204$ 
Teece DJ (2012) Dynamic capabilities: routines versus entrepreneurial action. J Manag Stud 49:13951401. https://doi.org/10.1111/j.1467-6486.2012.01080.x

Ter Wal ALJ, Criscuolo P, Salter A (2017) Making a marriage of materials: the role of gatekeepers and shepherds in the absorption of external knowledge and innovation performance. Res Policy 46:1039-1054. https://doi.org/10.1016/j.respol.2017.03.003

Tropp LR, Pettigrew TF (2016) Differential relationships between intergroup contact and affective and cognitive dimensions of prejudice. Pers Soc Psychol Bull. https://doi.org/10.1177/0146167205 274854

Trott P, Hartmann D (2009) Why "open innovation" is old wine in new bottles. Int J Innov Manag 13:715-736. https://doi.org/10.1142/S1363919609002509

Tucci CL, Chesbrough H, Piller F, West J (2016) When do firms undertake open, collaborative activities? Introduction to the special section on open innovation and open business models. Ind Corp Change 25:283-288. https://doi.org/10.1093/icc/dtw002

Turner JC, Brown RJ, Tajfel H (1979) Social comparison and group interest in ingroup favouritism. Eur J Soc Psychol 9:187-204. https://doi.org/10.1002/ejsp.2420090207

van de Vrande V, de Jong JPJ, Vanhaverbeke W, de Rochemont M (2009) Open innovation in SMEs: trends, motives and management challenges. Technovation 29:423-437. https://doi.org/10.1016/j. technovation.2008.10.001

von Hippel E (1994) "Sticky Information" and the Locus of Problem Solving: Implications for Innovation. Manag Sci 40:429-439. https://doi.org/10.1287/mnsc.40.4.429

von Briel F, Recker JC (2017) Lessons from a failed implementation of an online open innovation community in an innovative organization. MIS Q Exec 16:35-46

Walczuch R, Lemmink J, Streukens S (2007) The effect of service employees' technology readiness on technology acceptance. Inf Manage 44:206-215. https://doi.org/10.1016/j.im.2006.12.005

Weissenberger-Eibl MA (2018) Wissen, Können und Tun. Wie sich Zukunft nachhaltig gestalten lässt. In: Hildebrandt A, Neumüller W (eds) Visionäre von heute - Gestalter von morgen. Springer Gabler, pp 217-238

Weissenberger-Eibl MA (ed) (2019) Zukunftsvision deutschland: innovation für Fortschritt und Wohlstand. Gabler Verlag

Weissenberger-Eibl MA, Koch DJ (2013) Innovation - Technologie - Entrepreneurship: gestaltungssystem der frühen Phase des Innovationsprozesses, 1st edn. Cactus Group Verlag, Karlsruhe

Weissenberger-Eibl MA, Hampel T (2021) What do we have in-common? Overcoming the not-inventedhere syndrome through recategorisation. Int J Innov Manage 2150070

West J, Lakhani KR (2008) Getting clear about the role of communities in open innovation. Social Science Research Network, Rochester

West J, Salter A, Vanhaverbeke W, Chesbrough H (2014) Open innovation: the next decade. Res Policy 43:805-811. https://doi.org/10.1016/j.respol.2014.03.001

Yin RK (2018) Case study research and applications: design and methods, 6th edn. Sage Publications Ltd., Los Angeles

Zahay D, Hajli N, Sihi D (2017) Managerial perspectives on crowdsourcing in the new product development process. Ind Mark Manag. https://doi.org/10.1016/j.indmarman.2017.11.002

Zahra SA, George G (2002) Absorptive capacity: a review, reconceptualization, and extension. Acad Manage Rev 27:185-203. https://doi.org/10.2307/4134351 